\title{
Optimization Method for Container Quay Crane Operation Based on Energy Saving
}

\author{
Liu Leilei, Sun Lei, Zhao Dadi \\ Tianjin Research Institute for Water Transport Engineering, Key Laboratory of Environmental Protection Technology on Water \\ Transport, Ministry of Transport, Tianjin, China
}

\begin{abstract}
This paper studies the energy utilization of the quay crane, one of the major energy using equipment for the container terminal. We establish an optimization model for the loading and unloading of the quay crane, use the genetic algorithm to solve it, and verify the validity of the model by actual operation data of container terminals. The results show that the model has a significant effect on reducing energy consumption of quay cranes.
\end{abstract}

\section{Introduction}

The quay crane is the main equipment for the loading and unloading on container terminals. According to the statistics, the energy consumption of the quay crane accounts for about $35 \%$ of the energy consumption of the container loading and unloading. Therefore, it has a significant effect on reducing the energy consumption of the container terminals by means of improving the energy utilization efficiency.

The related researches mainly focused on improving the efficiency of quay crane operation, and established various models to solve the problems in quay crane scheduling. Considering all the related constraints of the quay crane operation, $\operatorname{Kim}[1]$ established a mixed integer programming model and proposed the optimal scheme using the branch and bound method to obtain the quay crane scheduling problem. Luigi[2] proposed that the quay crane scheduling problem be conceived as a lateral constraint vertex routing problem, and the process links between the vertices should be considered. Pasquale[3] presented a detailed model of quay crane scheduling, which covered important factors related to reality, such as the average operating rate, preparation time, security requirements, and priority relationships among container types. In order to minimize the operating time of the quay crane, Zhang[4] established a model and got the optimized operation line of the quay crane.

The above literatures are mainly aimed at minimizing the operation time. There are few researches on the optimization of quay crane operation with the aim of energy consumption optimization. In this paper, the optimization of quay crane operation under the energy saving angle is studied. The energy consumption of the quay crane is taken as a decision variable. Through the optimization, the efficiency of the quay crane can be improved, and the energy consumption can be reduced.

\section{Energy consumption model of quay crane}

\subsection{Model assumptions}

Based on the operation of the quay crane, the assumptions are put forward as follows [5].

(1) The operation of each bay is completed by one quay crane and it can't move to the next bay until the operation is completed.

(2) Compared with the loading and unloading operation time, the moving time of the quay crane is ignored.

\subsection{Parameter definitions}

(1) The relevant parameters in the model are defined as follows.

$Q=\{1,2, \ldots \mathrm{k}, \ldots, \mathrm{q}\}:$ The collection of quay crane. $\Omega$ : The collection of bay tasks. $P_{i}$ : Loading and unloading time of bay I. $T=\{1,2, \ldots \mathrm{t}\}$ : The collection of unit time. $h$ : The safety distance of the adjacent quay crane. $M$ : A large enough number. ${ }^{C_{w k}}$ : Energy consumption per unit time of quay crane $\mathrm{K}$ in standby time. ${ }^{C_{t k}}$ : Energy consumption per unit time of quay crane $\mathrm{K}$ in operation. $\omega$ : Energy consumption scenarios.

(2) The related decision variables in the model are defined as follows.

$t_{a}$ : Berthing time of ships. ${ }^{t_{s}}$ : Starting time of the service. ${ }^{t}$ : Ending time of the service. ${ }_{s i}$ : Starting time 
of operation at bay I. ${ }^{t_{e i}}$ : Ending time of operation at bay I. $E_{k}$ : A collection of bays loading and unloading operated by quay crane K. ${ }^{X_{i t k}}$ : If the task of bay $\mathrm{I}$ is served by quay crane $\mathrm{K}$, it is 1 , otherwise it is $0 .{ }^{Y_{i j k}}$ : If the task of bay I and $\mathrm{J}$ are served by quay crane $\mathrm{K}$, it is 1 , otherwise it is $0 .{ }^{Z_{i j k}}$ : If the task of bay I is before bay $\mathrm{J}$, it is 1 , otherwise it is $0 . f_{i k}$ : If the task of bay I is served first by quay crane $\mathrm{K}$, it is 1 , otherwise it is $0 .{ }^{V_{i j}}$ : If the task starting time of bay $\mathrm{J}$ is not earlier than the task ending time of bay $\mathrm{I}$, it is 1 , otherwise it is $0 . \mathrm{T}_{k}$ : The time span of the entire scheduling scheme.

\subsection{Modeling}

The low energy consumption model is based on the optimization of the energy consumption of quay crane as the objective function. It helps to assign the task unit and determine the sequence, so that the energy consumption of the quay crane can be lower.

$$
\begin{aligned}
& \min \sum_{\psi \in \Psi} P(\psi) \bullet\left[C_{t k} \sum_{k \in Q}\left(T_{k}(\psi)-W_{k}(\psi)\right)+C_{w k} \sum_{k \in Q} W_{k}(\psi)\right] \\
& \text { constraint conditions: } \\
& t_{s}=\min \left\{t_{s i}\right\}\{\forall i \in \Omega\} \\
& t_{e}=\min \left\{t_{e i}\right\}\{\forall i \in \Omega\} \\
& T_{k}(\psi) \leq T, k \in Q \\
& \sum_{k \in Q} X_{i t k}=1,(t \in T, i \in \Omega) \\
& \sum_{i \in \Omega} f_{i k}=1,(t \in T, k \in Q) \\
& \sum_{k \in Q} f_{i k} \leq 1,(t \in T, i \in \Omega) \\
& t_{s j}-\left(t_{s i}-p_{i}\right)+\left(1-Z_{i j k}\right) M \geq 0, \forall i, j \in E_{k}, k \in Q \\
& \sum_{j \in E_{k}} Z_{i j k} \leq 1, \forall i \in E_{k}, k \in Q \\
& \sum_{j \in E_{k}} Z_{j i k} \leq 1, \forall i \in E_{k}, k \in Q \\
& \sum_{j \in E_{k}} Z_{i j k}-\sum_{j \in E_{k}} Z_{j i k}=0, \forall i \in E_{k}, k \in Q \\
& M\left(V_{i j}+V_{j i}\right) \geq \sum_{k \in Q} k X_{i t k}-\sum_{q \in Q} q X_{j t k}+1, \forall i, j \in \Omega, i<j \\
& M\left(V_{i j}+V_{j i}\right) \geq \sum_{i \in \Omega} i X_{i t k}-\sum_{i \in \Omega} q X_{j t k}+h, \forall k, q \in Q, k<q \\
& Y_{i j k} \leq 0.5\left(X_{i t k}+X_{j t k}\right) \leq Y_{i j k}+0.5, \forall i, j \in E_{k}, k \in Q \\
& Y_{i j k}=Y_{j i k}, \forall i, j \in E_{k}, k \in Q
\end{aligned}
$$

The meaning of constraint conditions:

The formula (2) and (3) define the starting and ending time.

The formula (4) indicates that the completion time of each quay crane is less than the time span of the whole scheduling scheme.

The formula (5) indicates that every bay can only be operated by one quay crane.

The formula (6) ensures that each quay crane has only one initial operation bay.

The formula (7) ensures that one bay can only be the initial operation bay for one quay crane.
The formula (8) ensures that the starting time of the next task should be later than the completion time of the previous task.

The formula (9) and (10) ensure that there is only one consecutive preorder operation and one consecutive follow-up operation for each bay.

The formula (11) ensures that the operation of each quay crane is carried out in the prescribed order.

The formula (12) is the interference constraint. It ensures that the operating quay cranes can't cross each other.

The formula (13) is the safety distance constraint of the quay crane.

The formula (14) and (15) indicate the relationship

between $x_{i t k}$ and $X_{i j k}$. When

$x_{i t k}=x_{j t k}=1, x_{i j k}=x_{j i k}=1$.

\section{Genetic algorithm design}

\subsection{Chromosome encoding}

In this paper, the decimal method is used to encode, each chromosome represents 1 solution of the model. The Fig. 1 is the chromosome encoding with 10 bays and 2 quay cranes, and 0 represents the interval between different quay cranes.

$$
\begin{array}{rl|l|l|l|l|l|l|l|l|l|l|l|}
\hline \text { chromosome } & \mathbf{7} & \mathbf{5} & \mathbf{8} & \mathbf{9} & \mathbf{2} & \mathbf{3} & \mathbf{0} & \mathbf{6} & \mathbf{1} & \mathbf{4} & \mathbf{1} \\
\mathbf{0}
\end{array}
$$

Fig. 1. Description of chromosome coding

\subsection{Search space}

Under the constraints (5) (7), (9) (13) and (17), the search space of the genetic algorithm is $P_{b}^{b} \times C_{b-1}^{q-1}$, of which $b$ and $q$ represent the number of bays and quay cranes.

\subsection{Initial population and fitness function}

In order to avoid the early convergence, this paper uses the fitness calculation based on sorting. First, we calculate the objective function value of each individual in the population, and then arrange it in ascending order. The minimum of the objective function ranks first, the largest ranks $\mathrm{N}$ ( $\mathrm{N}$ is the population size). The fitness of the individual in position $\mathrm{I}$ is [6]:

$$
\text { Fitness (i) }=2-2(\mathrm{i}-1) /(\mathrm{N}-1)
$$

Formula (16) is fitness function, which effectively controls the replication probability of supernormal individuals and maintained population diversity. In the selection process, roulette selection mechanism is adopted.

\subsection{Crossover and mutation operation}

According to the characteristics of the model, sequential crossover is used in this paper [7], as shown in Fig. 2. 
Firstly, 2 points of tangency $\mathrm{X}$ and $\mathrm{Y}$ are selected randomly, and then the middle part is exchanged. Secondly, from the first gene after the second point of tangency Y, the original gene sequence is listed, and the existing genes are removed. Finally, the non-repeated gene sequence will be obtained from the first locations after point of tangency Y. S changes the distribution of quay cranes by means of chromosomal variation. In this paper, transposition variation is used to randomly select 2 genes in the operation sequence of different quay cranes, and the exchange gene is shown in Fig. 3.

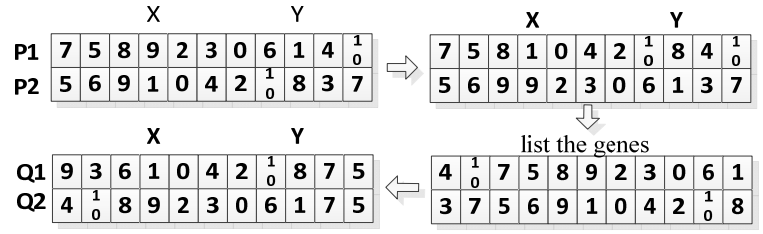

Fig. 2. Cross operation schematic diagram

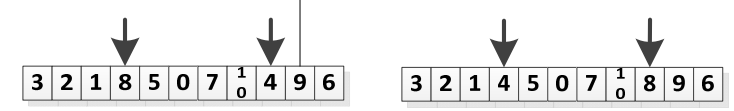

Fig. 3. Schematic diagram of mutation operation

\section{Application verification}

This application gives 20 bays, assigns 4 quay cranes, and keeps at least 2 bays safety distances between adjacent 2 quay cranes, that is, $h=2$. The parameters of genetic algorithm are: population size Pop $=50$, number of genetic iterations $G=200$, cross probability $P c=0.8$, and mutation probability $P m=0.1$. Other parameters are the same as mentioned earlier. The loading and unloading operations of bays are shown in Table 1.

Table 1. Loading and unloading operations

\begin{tabular}{|c|c|c|c|}
\hline Bay & Quantity & Bay & Quantity \\
\hline 1 & 10 & 11 & 40 \\
\hline 2 & 20 & 12 & 45 \\
\hline 3 & 19 & 13 & 8 \\
\hline 4 & 33 & 14 & 56 \\
\hline 5 & 12 & 15 & 68 \\
\hline 6 & 38 & 16 & 25 \\
\hline 7 & 29 & 17 & 18 \\
\hline 8 & 16 & 18 & 42 \\
\hline 9 & 26 & 19 & 15 \\
\hline 10 & 27 & 20 & 16 \\
\hline
\end{tabular}

The algorithm search space for this application is $2.3575 \mathrm{E}+21$. The genetic algorithm is designed by MATLAB program to solve the calculation. When the number of iterations reaches 105 times, the value of the objective function becomes stable and converges. The program running process takes $15.78 \mathrm{~s}$. The solution results are shown in Table 2 and Table 3.

Table 2. Optimization plan for operation energy consumption and standby energy consumption of quay crane

\begin{tabular}{|c|c|c|c|c|c|c|c|c|c|c|c|c|c|c|c|}
\hline \multicolumn{4}{|c|}{ quay crane 1} & \multicolumn{4}{|c|}{ quay crane 2} & \multicolumn{4}{|c|}{ quay crane 3} & \multicolumn{4}{|c|}{ quay crane 4} \\
\hline \multirow[b]{2}{*}{ Bay } & \multicolumn{3}{|c|}{ energy consumption } & \multirow[b]{2}{*}{ Bay } & \multicolumn{3}{|c|}{ energy consumption } & \multirow[b]{2}{*}{ Bay } & \multicolumn{3}{|c|}{ energy consumption } & \multirow[b]{2}{*}{ Bay } & \multicolumn{3}{|c|}{ energy consumption } \\
\hline & $\begin{array}{c}\text { Initi } \\
\text { al }\end{array}$ & $\begin{array}{c}\text { operatio } \\
n\end{array}$ & $\begin{array}{c}\text { endin } \\
\mathrm{g}\end{array}$ & & $\begin{array}{c}\text { Initi } \\
\text { al }\end{array}$ & $\begin{array}{c}\text { operatio } \\
n\end{array}$ & $\begin{array}{c}\text { endin } \\
\mathrm{g}\end{array}$ & & $\begin{array}{c}\text { Initi } \\
\text { al }\end{array}$ & $\begin{array}{c}\text { operatio } \\
n\end{array}$ & $\begin{array}{c}\text { endin } \\
\mathrm{g}\end{array}$ & & $\begin{array}{c}\text { Initia } \\
1\end{array}$ & $\begin{array}{c}\text { operatio } \\
\text { n }\end{array}$ & $\begin{array}{c}\text { endin } \\
\mathrm{g}\end{array}$ \\
\hline 1 & 0 & 10 & 10 & 5 & 0 & 12 & 12 & 10 & 0 & 27 & 27 & 16 & 0 & 25 & 25 \\
\hline 2 & 10 & 20 & 30 & $\begin{array}{l}\text { Beca } \\
\text { stand } \\
15 \mathrm{kV}\end{array}$ & $\begin{array}{l}\text { se of sa } \\
\text { y energ } \\
\text { na }\end{array}$ & $\begin{array}{l}\text { ty distance } \\
\text { consumpti }\end{array}$ & & 13 & 27 & 8 & 35 & 17 & 25 & 18 & 43 \\
\hline 3 & 30 & 19 & 49 & 8 & 27 & 16 & 43 & 14 & 35 & 56 & 91 & 18 & 43 & 42 & 85 \\
\hline 4 & 49 & 33 & 82 & 9 & 43 & 26 & 69 & 15 & 91 & 68 & 159 & 20 & 100 & 16 & 116 \\
\hline 6 & 82 & 38 & 120 & 11 & 69 & 40 & 109 & & & & & & & & \\
\hline 7 & 120 & 29 & 149 & 12 & 109 & 45 & 154 & & & & & & & & \\
\hline
\end{tabular}

Note: the unit of energy consumption in the table is kWh

Table 3. Optimization plan for operation energy consumption of quay crane

\begin{tabular}{|c|c|c|c|c|c|c|c|c|c|c|c|c|c|c|c|}
\hline \multicolumn{4}{|c|}{ quay crane 1} & \multicolumn{4}{|c|}{ quay crane 2} & \multicolumn{4}{|c|}{ quay crane 3} & \multicolumn{4}{|c|}{ quay crane 4} \\
\hline \multirow[b]{2}{*}{ Bay } & \multicolumn{3}{|c|}{ energy consumption } & \multirow[b]{2}{*}{ Bay } & \multicolumn{3}{|c|}{ energy consumption } & \multirow[b]{2}{*}{ Bay } & \multicolumn{3}{|c|}{ energy consumption } & \multirow[b]{2}{*}{ Bay } & \multicolumn{3}{|c|}{ energy consumption } \\
\hline & $\begin{array}{c}\text { Initia } \\
1\end{array}$ & $\begin{array}{c}\text { operatio } \\
n\end{array}$ & $\begin{array}{c}\text { endin } \\
\mathrm{g}\end{array}$ & & $\begin{array}{c}\text { Initia } \\
1\end{array}$ & $\begin{array}{c}\text { operatio } \\
\mathrm{n}\end{array}$ & $\begin{array}{c}\text { endin } \\
\mathrm{g}\end{array}$ & & $\begin{array}{c}\text { Initia } \\
1\end{array}$ & $\begin{array}{c}\text { operatio } \\
n\end{array}$ & $\begin{array}{c}\text { endin } \\
\mathrm{g}\end{array}$ & & Initial & $\begin{array}{c}\text { operatio } \\
n\end{array}$ & ending \\
\hline 1 & 1 & 0 & 10 & 10 & 5 & 0 & 12 & 12 & 11 & 0 & 40 & 40 & 14 & 0 & 56 \\
\hline 2 & 10 & 20 & 30 & 8 & 12 & 16 & 28 & \multicolumn{4}{|c|}{$\begin{array}{l}\text { Because of safety distance, standby } \\
\text { energy consumption } 16 \mathrm{kWh}\end{array}$} & 17 & 56 & 18 & 74 \\
\hline 3 & 30 & 19 & 49 & \multicolumn{4}{|c|}{$\begin{array}{l}\text { Because of safety distance, standby } \\
\text { energy consumption } 28 \mathrm{kWh}\end{array}$} & 13 & 56 & 8 & 64 & 18 & 74 & 42 & 116 \\
\hline 4 & 49 & 33 & 82 & 9 & 56 & 26 & 82 & 15 & 64 & 68 & 132 & 19 & 116 & 15 & 131 \\
\hline 6 & 82 & 38 & 120 & 10 & 82 & 27 & 109 & 16 & 132 & 25 & 157 & 20 & 131 & 16 & 148 \\
\hline
\end{tabular}




\begin{tabular}{|c|c|c|c|c|c|c|c|c|c|c|c|c|c|c|c|}
\hline \multicolumn{4}{|c|}{ quay crane 1} & \multicolumn{4}{|c|}{ quay crane 2} & \multicolumn{4}{|c|}{ quay crane 3} & \multicolumn{4}{|c|}{ quay crane 4} \\
\hline \multirow[b]{2}{*}{ Bay } & \multicolumn{3}{|c|}{ energy consumption } & \multirow[b]{2}{*}{ Bay } & \multicolumn{3}{|c|}{ energy consumption } & \multirow[b]{2}{*}{ Bay } & \multicolumn{3}{|c|}{ energy consumption } & \multirow[b]{2}{*}{ Bay } & \multicolumn{3}{|c|}{ energy consumption } \\
\hline & $\begin{array}{c}\text { Initia } \\
1\end{array}$ & $\begin{array}{c}\text { operatio } \\
n\end{array}$ & $\begin{array}{c}\text { endin } \\
\mathrm{g}\end{array}$ & & $\begin{array}{c}\text { Initia } \\
1\end{array}$ & $\begin{array}{c}\text { operatio } \\
n\end{array}$ & $\begin{array}{c}\text { endin } \\
\mathrm{g}\end{array}$ & & $\begin{array}{c}\text { Initia } \\
1\end{array}$ & $\begin{array}{c}\text { operatio } \\
n\end{array}$ & $\begin{array}{c}\text { endin } \\
\mathrm{g}\end{array}$ & & Initial & $\begin{array}{c}\text { operatio } \\
n\end{array}$ & ending \\
\hline 7 & 120 & 29 & 149 & 12 & 109 & 45 & 154 & & & & & & & & \\
\hline
\end{tabular}

Note: the unit of energy consumption in the table is kWh

Compared with the consideration of operation energy consumption only, the optimization scheme considering the operation and standby energy consumption has obvious advantages in controlling the standby energy of the quay cranes. The standby energy for the quay cranes is only $15 \mathrm{kWh}$, which is $29 \mathrm{kWh}$ less than the consideration of operation energy consumption only. Meanwhile, after optimization, the total energy consumption of quay crane 4 is reduced from $148 \mathrm{kWh}$ to $116 \mathrm{kWh}$. Therefore, the optimization scheme can reduce the loading and unloading energy consumption of container terminals.

\section{Conclusions}

This paper takes scheduling problem with single ship and multi quay crane as the research object. The energy consumption of the quay crane is taken as a decision variable. We use decimal method to encode genetic algorithm and use the method of generating the initial population randomly to increase the individual diversity of the initial population, so as to avoid falling into local optimal. In this paper, 231 sets of energy consumption and operation data of a container terminal in Tianjin are selected and analyzed. The results show that the model has a significant effect on reducing the standby energy consumption of the quay cranes. It should be noted that this optimization model still has a comprehensive impact on the factors such as the scheduling of the container trucks and the gantry cranes. We will continue to conduct long-term data monitoring and analysis, and constantly optimize the model.

\section{Acknowledgment}

Fund Project, National Key R\&D Program of China 2016YFE02044800, Central-level nonprofit scientific research institutes basic research project special funds TKS170207

\section{References}

1. Kim KH, Park Y. Eur. J. Oper. Res. 752, 156(2004)

2. Luigi M, Jean Francois C, et al. Nav. Res. Log. 45, 53(2006)

3. Pasquale L, Roberto T, Frank M. Comput. Oper. Res. 2063,39(2012)

4. Y.H. Zhang, C.J. Liang. J. Wuhan Univ. Technol. $64,34(2012)$

5. Z.Q. Fan, M.L. Le. J. Syst. \& Manage.120,22(2013)

6. Whitley D. ICGA, 116 (1989)

7. Davis L. IJCAI,162(1985) 